\title{
Detecting Land Cover Changes in the Western Sudan Using Landsat Data from 1994 to 2015
}

\author{
Mohammed Abdelmanan $^{\mathrm{a}}$, Xiaoli Zhang ${ }^{\mathrm{b}^{*}}$, Mohammed Ishag $^{\mathrm{c}}$ \\ Official email address: m.abdelmanan@zalingei.edu.sd \\ ${ }^{a}$ Faculty of Forestry Sciences, University of Zalingei, P.O.Box 06, Darfur, Sudan \\ ${ }^{b}$ Beijing Key Laboratory of Precision Forestry, College of Forestry, Beijing Forestry \\ University, Beijing 100083, China \\ ${ }^{c}$ College of Forestry and Range Science, Sudan University of Science and Technology, P.O.Box 407, Khartoum, Sudan
}

\begin{abstract}
Detecting Land cover (LC) change at local scale is needed for a wide range of applications, such as deforestation, land degradation and desertification. LC changes based on anthropogenic activities, negatively impact the patterns of climate and socio-economic dynamics at both local and global scales. In this study, LC changes investigated using satellite remote sensing imagery and Geographic Information System (GIS) in West Kordofan Region of Sudan. To achieve the purpose, firstly a supervised classification is performed to the satellite images of Landsat acquired in 1994 and 2015. The classification of the six reflective bands of two Landsat images is carried out by using maximum likelihood techniques with the aid of ground points data collected from detailed field survey across the study area in 2015. The second step focused on LC changes by applying change detection comparison (pixel by pixel). The results showed that massive LC changes have occurred in bareland (50\%), Sand dunes (28.7\%), Acacia trees and Shrubs (-13.9\%) and dense forest (7.5\%), areas between 1994 and 2015. It was clearly seen that the LC changes mostly occurred in bareland.
\end{abstract}

Published by IJRP.ORG. Selection and/or peer-review under responsibility of International Journal of Research Publications (IJRP.ORG)

Keywords: Mapping change, satellite images, semi-desert area, West Kordofan

\section{Introduction}

Land Use Land Cover (LULC) plays a critical role in local and global environmental change studies (Mohammed et al., 2018; Belay and Mengistu, 2019; Hailu, Mammo and Kidane, 2020; Nse, Okolie and Nse, 2020). LU and anthropogenic activities have largely resulted in deforestation, land degradation, deterioration, desertification, and habitat loss (Ikazaki, 2015; Hishe et al., 2020). These environment issues are almost connected to LULC changes (Ketema et al., 2020; Liu et al., 2020). This pressure and the associated LULC changes are mostly followed by mis-management of natural resources, which, in most cases, occurred in developing countries (Nse, Okolie and Nse, 2020). In these countries, unplanned human activities and unguided planning, traditional rained agricultural practices can increase when decision-makers disregard the 
needs of local population to sustain their livelihood. Therefore, availability of LULC changes information could provide important inputs for planning.

The increasing socio-economic needs and growing population creates a marvelous pressure on LCLC (Brink and Eva, 2009; Gross et al., 2013; Elagib and Mansell, 2016). LULC are expressively altering the Earth surface and this has had a profound effect on natural environment over time (Ketema et al., 2020). Also, they have continue to explore and exploit the natural resources in their environment and these have brought a massive impact in LULC changes (Pitman et al., 2004; Assessment, 2012; Jamali et al., 2015; Ketema et al., 2020). LU can be measured to be reflecting the degree of human activities that are directly related to land and making use of its resources which tend to vary over time and scale (Pitman et al., 2004; Assessment, 2012; Gross et al., 2013; Jamali et al., 2015; Ketema et al., 2020). The extent of LULC changes are varies with the time being investigated, the geographical location, and more significantly the nature of LC. However, data on LULC may not, therefore, be easily collected except with relevant remote sensing technologies and techniques.

Satellite remote sensing data integrated with Geographical Information System (GIS) are powerful tools to generate an accurate and timely information on the spatial distribution of LULC changes over small or large scale areas (Antwi, 2009; Mohammed et al., 2018; Tadese et al., 2020). GIS offer a flexible environment for collecting, storing, displaying and analyzing digital data needed for change detection (Hishe et al., 2020). Satellite remote sensing data are the practical data resources for GIS. Satellite remotely sensed data have been used extensively in LULC change studies due to the rich archive, free of cost and its spectral resolutions.

The aim of change detection process is to identify LULC on digital images that change object of interest between two or more dates (Muttitanon and Tripathi, 2005). There are many methods and techniques developed such as post-classification comparison, image ratio, image regression, and manual on-screen digitization of change, principal components analysis and multi-date image classification (Lu et al., 2005). A numerous studies have highlighted that post-classification comparison was recognized to be the most accurate approach due to indicating the nature of the changes. In this study, change detection comparison (pixel by pixel) technique was applied to LC map generated from satellite remotely sensed data (Marland et al., 2003; Gross et al., 2013; Jamali et al., 2015; Belay and Mengistu, 2019; Ketema et al., 2020).

This study aimed to analyze LC changes using satellite imagery data and GIS in West Kordofan Region, Sudan. In order to achieve this objective, Landsat Thematic Mapper (TM) and Enhanced Thematic Mapper (ETM+) data acquired on November 1994, and November 2015, respectively, were used. Maximum likelihood classification and change detection comparison strategy were applied to identify LC changes. 


\section{Materials and Methods}

\subsection{Study Area}

The study areas involve six localities: En Nahud, Ghubaysh, El Fula, Laqawa, Muglad and Abyei (Fig. 1) that make-up West Kordofan Region. It is located on the west south part of Sudan between latitude $9{ }^{\circ}-14{ }^{\circ} \mathrm{N}$ and longitude $27^{\circ}-29^{\circ} \mathrm{E}$ with altitude ranging from 350 to 1000 meter above sea level (Mohammed et al., 2018). West Kordofan Region covers nearly $113780.8224 \mathrm{~km} 2$, with $70 \%$ of its total area is sandy soil and $30 \%$ is clay soil. West Kordofan has a semi-arid climate very dry in the north part with average temperature of $36.3^{\circ} \mathrm{C}$. The annual rainfall varies from north to south with average of $240.5 \mathrm{~mm}$. The vegetation cover are mostly located in the south part of West Kordofan due to increase of annual rainfall. The study area contains a few seasonal streams locally known as (Wadies), which generally dried over dry season. The agricultural lands are located in the middle of the study area due either to desert encroachment from north to south or the on-going conflict in south part. The main agricultural crops are groundnuts, millet and hibiscus being among the most important crops. Livestock husbandry is an important component of rural livelihood in West Kordofan as well as Gum Arabic production. Desert encroachment and land degradation is often attributed to limited of vegetation cover in north part as well as overgrazing and the intensity and methods of traditional agricultural practices.

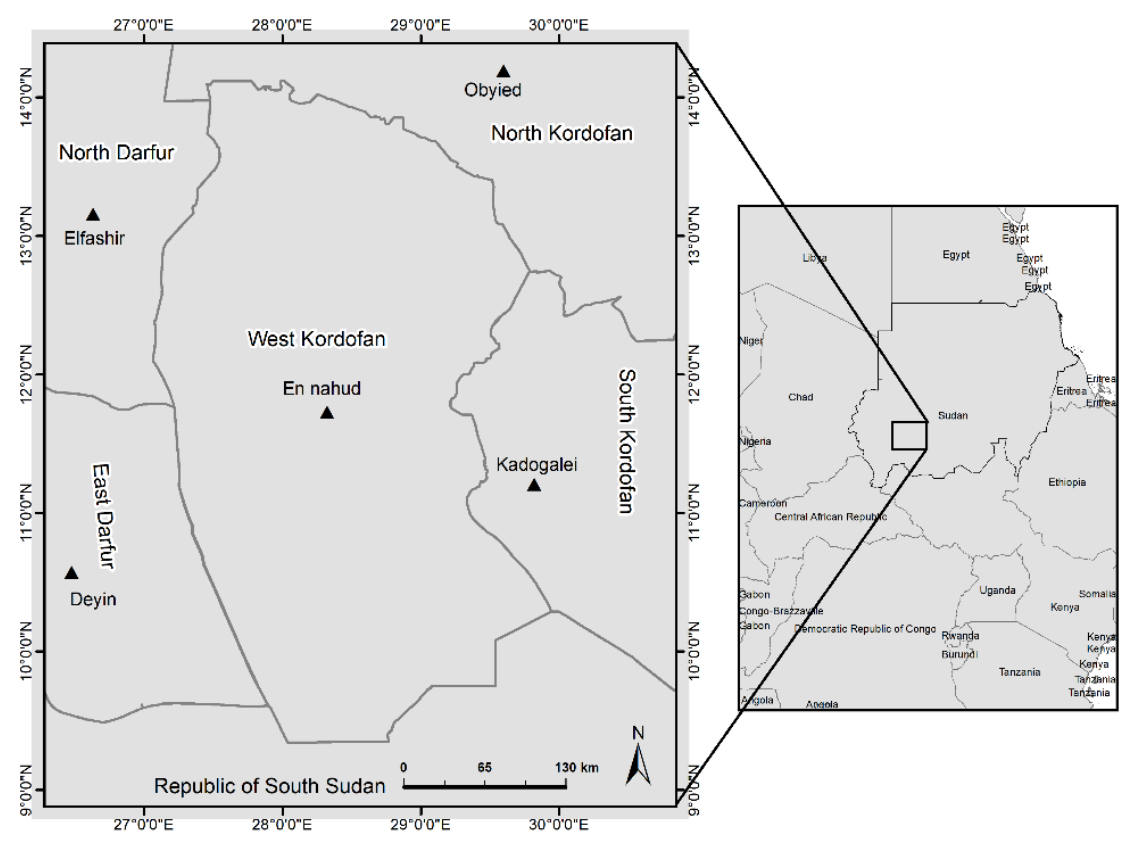


Fig. 1. Location of the study area.

\subsection{Data}

Landsat TM and Landsat ETM+ (Path/Row: 176/50, 176/51, 176/52, 176/53, 175/51, 175/52,175/53 and174/53) were used in this study (Table 1). All the satellite images were downloaded from United State Geological Survey USGS. The dates of all images were chosen to be as closely as possible in the same season.

\subsection{Remote sensing images and pre-processing}

For change detection, several requirements of pre-processing, for example, geometric correction, radiometric and atmospheric corrections are the most essential to avoid spurious results produced from these issues (Lu et al. 2004). In this study, all downloaded satellite data were level-1 products which were rectified, geometrically and topographically corrected. All images were converted from digital numbers (DNs) to top of atmosphere reflectance using the method suggested by (Chander, Markham and Helder, 2009). Dark object subtraction was used to correct atmospheric effects. Mosaic was applied for the paths and rows: 176/50, $176 / 51,176 / 52,176 / 53,175 / 51,175 / 52,175 / 53$ and174/53. All the images pre-processing steps were carried out using software ENVI 5.3 and ArcGIS 10.2.

\subsection{Image classification and accuracy assessment}

In this study, four major LC categories were identified as dense forest, bareland, Acacia trees and shrubs and Sand dunes. Two dated Landsat images were compared supervised classification method. In this supervised classification method, two images with different dates are independently classified.

Accuracy assessment was significant for a map generated from any remote sensing data. Error matrix is the most common way to present the accuracy of classified images. Overall, user's and producer's accuracies, and Kappa value were then generated from the error matrices. The Kappa value incorporates the off-diagonal elements of the error matrices and represents agreement acquired after removing the proportion of agreement that could be expected to occur by chance. However, the Kappa value was calculated using the following equation.

$$
\widehat{k}=\frac{\sum_{1-1}^{r} P_{i i}-\sum_{1-1}^{r} P_{i+} \times P_{+i}}{1-\sum_{1-1}^{r} P_{i+} \times P_{+i}}
$$


Here, $r=$ the number of rows in the error matrix

$\mathrm{P}_{-} \mathrm{ii}=$ the proportion of pixels in row ' $\mathrm{r}$ ' and column ' $\mathrm{i}$ '

$P_{-}(i+)=$ the proportion of the marginal total of row ' $i$ '

P_ $(+i)=$ the proportion of the marginal total of column ' $i$ '

Table 1. Satellite imagery used in this study.

\begin{tabular}{lllll}
\hline Date & Sensor & Spatial resolution & Spectral band & Format \\
\hline $28 / 11 / 1994$ & TM & 30 & 7 & GeoTiff \\
$23 / 11 / 2015$ & ETM+ & 30 & 7 & GeoTiff \\
\hline
\end{tabular}

These data were collected from the official website of US Geological Survey (USGS)

(http://glovis.usgs.gov).

\section{Results and discussion}

\subsection{LC classification and accuracy assessment}

In this study, 73 polygons for Landsat TM 1994 and 69 polygons for Landsat ETM+ 2015 were randomly selected to assess the classification accuracy. Table 2 shows the overall, user's, producer's accuracies and Kappa value. The overall accuracy of classified images dated 1994 was $95.6 \%$ and that of the image dated 2015 was 93.2\%, and the Kappa value were 94.3\% and 92.6\%, respectively. In 1994 and 2015 classified maps, user's and producer's accuracies of individual classes were enormously high, ranging from $80 \%$ to $97.6 \%$ and $83.3 \%$ to $93.01 \%$, respectively. The classification accuracies had been turned out to be higher than expected. Classification processes become more difficult particularly due to the fact that there are only LC map of Sudan but no sufficient ground points data for the periods of 1994. But having dense forest, located in south border and sand dunes in the north part of the study area, made it possible to assess the classification outcomes reliably.

Table 2. Accuracy assessment of classified satellite imagery for the years 1989, 2000, and 2015.

\begin{tabular}{lllll}
\hline LULC categories & 1994 & \multicolumn{2}{l}{2015} \\
\cline { 2 - 5 } & Producer's & User's accuracy & Producer's & User's accuracy \\
& accuracy $(\%)$ & $(\%)$ & accuracy $(\%)$ & $(\%)$ \\
\cline { 2 - 5 } Dense forest & 94.41 & 93.01 & 92.51 & 88.84 \\
Bareland & 88.93 & 90.12 & 91.10 & 89.61 \\
\hline
\end{tabular}




\begin{tabular}{lllll}
\hline Acacia trees and Shrubs & 97.61 & 91.62 & 93.23 & 87.50 \\
Sand dunes & 80.00 & 83.32 & 89.74 & 84.51 \\
\hline Overall accuracy (\%) & 95.60 & & 93.27 \\
\hline Kappa Coefficient & 0.943 & 0.926 & \\
\hline
\end{tabular}

\subsection{LC change in West Kordofan Region}

The results of image classification showed that the total land area of West Kordofan Region was 113780.8224 $\mathrm{km}^{2}$. Individual class area and change statistic for the years 1994 and 2015 are presented in Table 3. From 1994 to 2015, dense forest and Acacia trees and shrubs decreased $5707.5525 \mathrm{~km}^{2}(7.5 \%)$ and $10584.5526 \mathrm{~km}^{2}$ (13.9\%), respectively. On the other hand, bareland and sand dunes increased $38199.6738 \mathrm{~km}^{2}(50 \%)$ and $21907.5687 \mathrm{~km}^{2}$ (28.7\%) from 1994 to 2015. Therefore, the change in dense forest and Acacia trees and Shrubs areas in course of time are meant by the change occurred in vegetation cover in 21 years. As seen in Table 3, while the areas well qualified for vegetation cover was $39673.4931 \mathrm{~km}^{2}$ in 1994, this number decreased $7.5 \%$ and $13.9 \%$ and became $23381.388 \mathrm{~km}^{2}$ in 2015 . On the other hand there was $21907.5687 \mathrm{~km}^{2}$ $(28.7 \%)$ increased in sand dunes, in that area the increase from $39084.4998 \mathrm{~km}^{2}$ to $60992.0685 \mathrm{~km}^{2}$. The decrease in dense forest areas and Acacia trees and Shrubs and increase in sand dunes areas are almost the same. This given data clearly state that the increase in sand dunes and decrease in dense forest and Acacia trees and Shrubs are mostly result in deforestation which means some forest areas were removed and converted to other type of LU or to desert or semi-desert areas. However, it's usual that this phenomena occurs in arid and semi-arid regions, with less rainfall and repeated period of droughts. The total annual rainfall in West Kordofan Region is $300-400$ mm, which makes West Kordofan Region a semi-arid area.

Table 3. Spatial coverage of various LC categories between 1994 and 2015.

\begin{tabular}{|c|c|c|c|c|}
\hline \multirow[t]{2}{*}{ LULC categories } & \multicolumn{2}{|c|}{$\begin{array}{l}\text { Spatial coverage of different LULC categories in } \\
\mathrm{km} 2\end{array}$} & \multirow{2}{*}{$\begin{array}{l}\text { Change area } \\
\text { /km2 } \\
1994-2015\end{array}$} & \multirow{2}{*}{$\begin{array}{l}\begin{array}{l}\text { Annual } \\
\text { change }\end{array} \\
1994-2015\end{array}$} \\
\hline & 1994 & 2015 & & \\
\hline Dense forest & 12419.8452 & 6712.2927 & -5707.5525 & -271.7882143 \\
\hline Bareland & 13115.2608 & 51314.9346 & 38199.6738 & 1819.032086 \\
\hline Acacia trees and & 27253.6479 & 16669.0953 & -10584.5526 & -504.0263143 \\
\hline \multicolumn{5}{|l|}{ Shrubs } \\
\hline Sand dunes & 39084.4998 & 60992.0685 & 21907.5687 & 1043.217557 \\
\hline Total & 113780.8224 & 113780.8224 & & \\
\hline
\end{tabular}



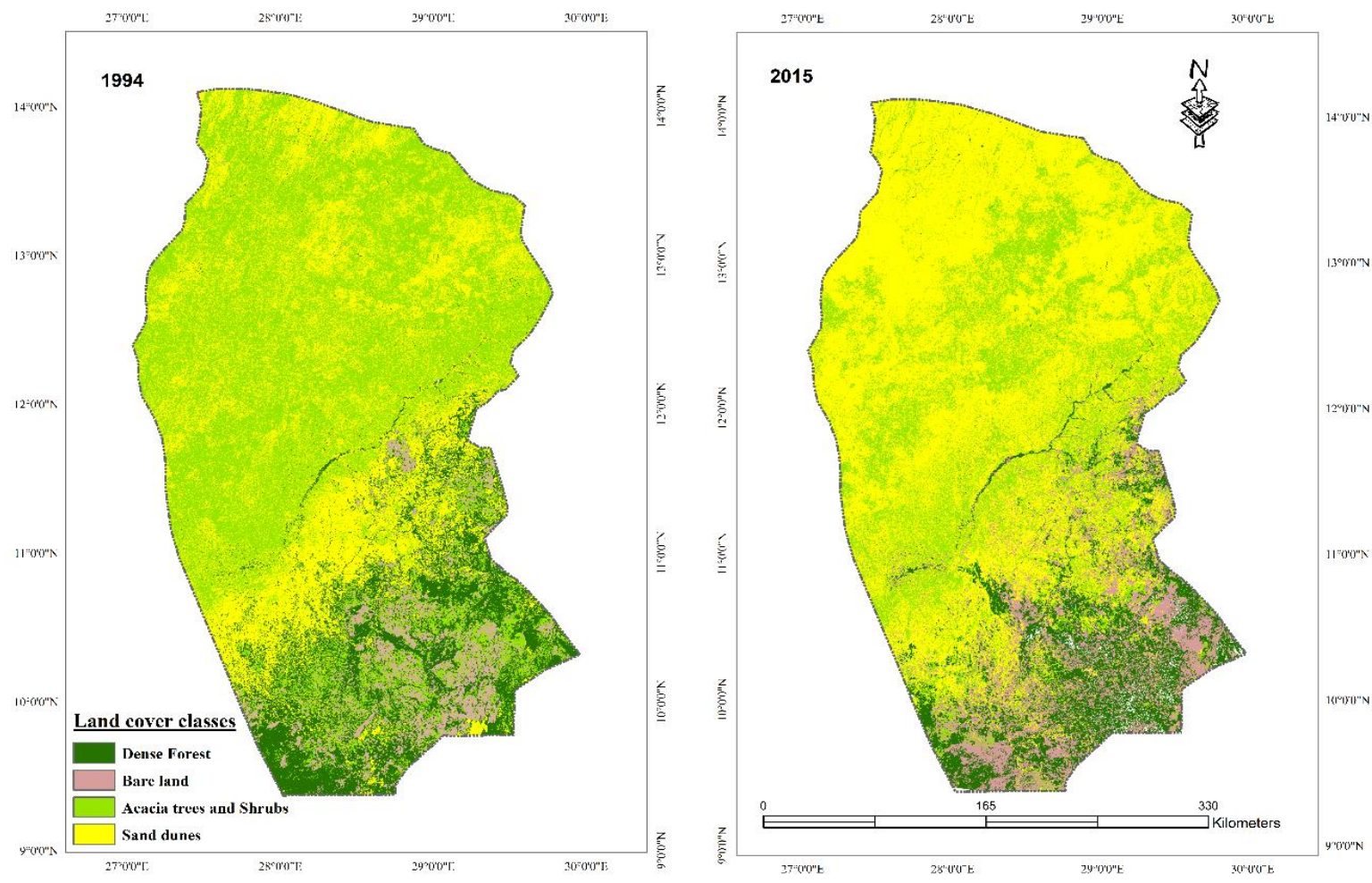

Fig.2. Classified maps for 1994 and 2015

Dense forest were typically located in the south part and along seasonal water courses within the study area, and the dense forest are less than other kinds of LC categories. The sand are dominated in the north part with $900 \mathrm{~m}$ of altitude (Mohammed et al., 2018), and the sand dunes area is more than the others types of LC.

In most parts of West Kordofan Region, negative trends in the sand dunes increase were shown, while vegetation cover decrease became an indicator of desert north border moving to south (Elagib and Mansell, 2016) and showed a negative impact on LC change. In addition, there was no protection measures in study area. As the results we assumed that in this region, the extensive creep of sand and the anthropogenic activities, the level of which reached the ecosystem carrying capacity, caused negative effects on biodiversity. This is very common in developing countries (Brink and Eva, 2009; Gross et al., 2013; Hailu, Mammo and Kidane, 2020) and could also verified by empirical studies and case analyses. For example, Ethiopia experienced a decline in vegetation caused by population growth, economic growth and rapid urban expansion, from 1989-2001, while in Cameroon, the human population was strongly responsible for LC change and degradation (Mertens and Lambin, 2000). 


\section{Conclusion}

This paper aimed to investigate LC changes occurred in West Kordofan Region between 1994 and 2015 using satellite remotely sensing data and GIS. The main change observed for the time period of 1994-2015 was that the area of Sand dunes, was increased about $21907.5687 \mathrm{~km} 2$ (28.7\%) of the total changed area. Dense forest and Acacia trees and Shrubs were decreased $16292.11 \mathrm{~km} 2$. The most imperative reason for this is that the intensive human activities (traditional rain-fed agricultural practices, grazing, and trees cutting). Since there had been very limited natural resources in the study area, and repeated periods of drought, those exploited areas were naturally turned into semi-desert of desert. Moreover, the climate pattern of the study area is susceptible for desertification.

Another challenge is some problems faced in identifying LC using remotely sensed data in West Kordofan Region. The complexity of vegetation cover and negative climate conditions are essential reasons for those problems. For this reason, it was relatively hard to find suitable and usable satellite remote sensing data. These problems had been tried to be eliminated by independently performing supervised classification change detection technique to both images.

\section{Acknowledgements}

This work was supported by the National key Research and Development program of China (2017YFD0600902). The authors would like to thank USGS for providing free access to Landsat data.

\section{References}

Antwi, E. K., 2009. Integrating GIS and remote sensing for assessing the impact of disturbance on habitat diversity and land cover change in a post-mining landscape; Integrative Nutzung von GIS und Fernerkundung zur Erfassung der Auswirkung von Störung der Habitatdiversität', (July 2009). Available at: https://opus4.kobv.de/opus4-btu/frontdoor/index/index/docId/670.

Assessment, C. C., 2012. Bangladesh Environmental and Climate Change Assessment Prepared for IFAD 's Country Strate gic Opportunities Programme 2012-2018', (3213).

Belay, T. and Mengistu, D. A., 2019. Land use and land cover dynamics and drivers in the Muga watershed, Upper Blue Nile basin, Ethiopia', Remote Sensing Applications: Society and Environment. Elsevier B.V., 15, p. 100249. doi: 10.1016/j.rsase.2019.100249.

Brink, A. B. and Eva, H. D., 2009. Monitoring 25 years of land cover change dynamics in Africa: A sample based remote sensing approach', Applied Geography. Elsevier Ltd, 29(4), pp. 501-512. doi: 10.1016/j.apgeog.2008.10.004.

Chander, G., Markham, B. L. and Helder, D. L., 2009. Summary of current radiometric calibration coefficients for Landsat MSS, TM, ETM+, and EO-1 ALI sensors', Remote Sensing of Environment. Elsevier Inc., 113(5), pp. 893-903. doi: 10.1016/j.rse.2009.01.007.

Elagib, N. A. and Mansell, M. G., 2016. Climate impacts of environmental degradation in Sudan Author (s): Nadir Ahmed Elagib and Martin G . Mansell Published by: Springer Stable URL : http://www.jstor.org/stable/41147481 REFERENCES Linked references are available on JSTOR for this article : ', 50(4), pp. 311-327.

Gross, D. et al., 2013, Monitoring land cover changes in African protected areas in the 21st century', Ecological Informatics. Elsevier B.V., 14, pp. 31-37. doi: 10.1016/j.ecoinf.2012.12.002.

Hailu, A., Mammo, S. and Kidane, M., 2020. Dynamics of land use, land cover change trend and its drivers in Jimma Geneti District, Western Ethiopia', Land Use Policy. Elsevier Ltd, 99, p. 105011. doi: 10.1016/j.landusepol.2020.105011. 
Hishe, H. et al., 2020. Analysis of Land Use Land Cover Dynamics and Driving Factors in Desa'a Forest in Northern Ethiopia', Land Use Policy. Pergamon, p. 105039. doi: 10.1016/j.landusepol.2020.105039.

Ikazaki, K., 2015. Desertification and a new countermeasure in the Sahel, West Africa', Soil Science and Plant Nutrition, 61(3), pp. 372383. doi: 10.1080/00380768.2015.1025350.

Jamali, S. et al., 2015. Detecting changes in vegetation trends using time series segmentation', Remote Sensing of Environment. Elsevier Inc., 156, pp. 182-195. doi: 10.1016/j.rse.2014.09.010.

Ketema, H. et al., 2020. Quantifying smallholder farmers' managed land use/land cover dynamics and its drivers in contrasting agroecological zones of the East African Rift', Global Ecology and Conservation. Elsevier B.V., 21, p. e00898. doi: 10.1016/j.gecco.2019.e00898.

Liu, S. et al., 2020. Understanding Land use/Land cover dynamics and impacts of human activities in the Mekong Delta over the last 40 years', Global Ecology and Conservation. Elsevier B.V., 22, p. e00991. doi: 10.1016/j.gecco.2020.e00991.

Lu, D. et al., 2005. Land-cover binary change detection methods for use in the moist tropical region of the Amazon: A comparative study', International Journal of Remote Sensing. Taylor and Francis Ltd., 26(1), pp. 101-114. doi: 10.1080/01431160410001720748.

Marland, G. et al., 2003. The climatic impacts of land surface change and carbon management, and the implications for climate-change mitigation policy', Climate Policy, 3(2), pp. 149-157. doi: 10.1016/S1469-3062(03)00028-7.

Mertens, B. and Lambin, E. F., 2000. Land-Cover-Change Trajectories in Southern Cameroon', Annals of the Association of American Geographers. Blackwell Publishing Inc., 90(3), pp. 467-494. doi: 10.1111/0004-5608.00205.

Mohammed, A. H. et al., 2018. Mapping land cover change in spatial patterns of semi-arid region across West Kordofan, Sudan using landsat data', Applied Ecology and Environmental Research. Corvinus University of Budapest, 16(6), pp. 7925-7936. doi: 10.15666/aeer/1606_79257936.

Muttitanon, W. and Tripathi, N. K., 2005. Land use/land cover changes in the coastal zone of Ban Don Bay, Thailand using Landsat 5 TM data', International Journal of Remote Sensing. Taylor and Francis Ltd., 26(11), pp. 2311-2323. doi: $10.1080 / 0143116051233132666$.

Nse, O. U., Okolie, C. J. and Nse, V. O., 2020. DYNAMICS OF LAND COVER, LAND SURFACE TEMPERATURE AND NDVI IN UYO CAPITAL CITY, NIGERIA', Scientific African. Elsevier BV, p. e00599. doi: 10.1016/j.sciaf.2020.e00599.

Pitman, A. J. et al., 2004. Impact of land cover change on the climate of southwest Western Australia', Journal of Geophysical Research Atmospheres, 109(18), pp. 1-12. doi: 10.1029/2003JD004347.

Tadese, M. et al., 2020. Mapping of land-use/land-cover changes and its dynamics in Awash River Basin using remote sensing and GIS', Remote Sensing Applications: Society and Environment. Elsevier B.V., 19, p. 100352. doi: 10.1016/j.rsase.2020.100352. 